1) L. Marton ; Phys. Rev. 85, 1057 (1952).

L. Marton, J. A. Simpson and J. A. Suddeth; Phys. Rev. 90, 490 (1953).

2) J. R. Simpson ; Rev. Sci. Inst. 25, 1099 (1954).

3) G. Möllenstedt and H. Düker ; Z. Phys. 145, 377 (1956).

4) T. Hibi and S. Takahashi; J. Electronmicroscopy 3, 129 (1963).

5) E. Kerschbaumer ; Z. Phys. 201, 200 (1967).

6) B. Okkerse ; Phil. Res. Rep. 18, 413 (1963).

7) U. Bonse and M. Hart ; Z. Phys. 189,151 (1966).

8) K. Kohra and S. Kikuta ; Acta Cryst. A24, 200 (1968).

9) U. Bonse and M. Hart ; Appl. Phys. Letters 6, 155 (1965) ; 7, 99 (1965) ; Z. Phys. 188 154 (1965).

10) U. Bonse and M. Hart ; Z. Phys. 194, 1 (1966).

11) U. Bonse and M. Hart ; Acta Cryst. A24, 240 (1968).

12) N. Kato and S. Tanemura; Phys. Rev. Letters 19, 22 (1967).

13) 岸野正剛; 私信

14) U. Bonse and M. Hart ; Z. Phys. 190, 455 (1966).

15) J. Chikawa ; Appl. Phys. Letters 7, 193 (1965).

16) A. R. Lang and V. F. Miuscov; Appl. Phys. Letters 7, 214 (1965).

17) J. Brádler and A. R. Lang; Acta Cryst. A24, 246 (1968).

18）松下, 菊田, 高良, 岸野, 杉田; 応用物理学会 (1968-4).

日本結晶学会誌 $10,171(1968)$

\title{
構造解析における統計法の応用
}

（I）対称中心のある場合

中 津 和 三*

1. はじめに

1963 年以来, 記号の和の方法 (symbolic addition method) といわれる統計的直接位相決 定法の 1 つが主として Karle らによって開発され，対称中心のある結晶については多数の 成功例が報告されている．また，対称中心のない場合についても数例の報告がある.ここで は方法の概略と共に, 最近筆者らが3つの結晶について試みた解析例を簡単に紹介しよう.

\section{2. 規格化構造因子}

symbolic addition 法においては，直接法でしばしば用いられるユニタリ一構造因子より も，式(1)で定義される規格化構造因子 (normalized structure factor, 以下 E factor と略す) が用いられる。

$$
\left|E_{h}\right|^{2}=\left|F_{h}\right|^{2} / \varepsilon \sum_{i=1}^{N} f_{i}(\boldsymbol{h})^{2}
$$

$*$ 関西学院大学理学部 
$\varepsilon$ は空閪閐の extinction によって異なる因子で， たとえば $P 2_{1} / c$ では $h 0$ $l, 0 k 0$ に対しては $\varepsilon=2$, その他の場合には $\varepsilon=1$ となる.Nは単位格子中 の原子数である.E factor は表1に示すような性質 をもっているので, これ らから対称心の有無を判 定することもできる.

\section{3. 位相決定法}

symbolic addition 法
表 1 規格化構造网子の平均之統計

\begin{tabular}{|c|c|c|c|c|c|c|}
\hline & \multicolumn{2}{|c|}{ 理＼cjkstart論＼cjkstart値 } & \multicolumn{2}{|c|}{ 実 } & 倪 & \\
\hline & \multirow{2}{*}{$\begin{array}{l}\text { 対称心 } \\
\text { のむる } \\
\text { 場台 }\end{array}$} & \multirow{2}{*}{$\begin{array}{l}\text { 対称心 } \\
\text { のない } \\
\text { 場台 }\end{array}$} & \multicolumn{2}{|c|}{$\begin{array}{l}\text { 対称心の } \\
\text { むる場台 }\end{array}$} & \multicolumn{2}{|c|}{$\begin{array}{l}\text { 対称心の } \\
\text { な、場合 }\end{array}$} \\
\hline & & & $\begin{array}{c}\text { 結晶A } \\
P^{2} 2_{1} / \mathrm{c}\end{array}$ & $\left|\begin{array}{c}\text { 結晶 } \mathrm{B} \\
P 2_{1} \mathrm{n}\end{array}\right|$ & $\mid \begin{array}{c}\text { 結晶 } \mathrm{C}^{* *} \\
P^{2}{ }_{1}\end{array}$ & $\mid \begin{array}{l}\text { 結晶 } \mathrm{D}^{* *} \\
P 2_{1} 2_{1} 2_{1}\end{array}$ \\
\hline$<|E|^{2}>$ & 1.000 & 1.000 & $1.000 *$ & $1.000 *$ & $0.99 \frac{1}{1}$ & 0.989 \\
\hline$<|E|>$ & 0.798 & 0.886 & 0.726 & 0.777 & 0.884 & 0.871 \\
\hline$<\left|E^{2}-1\right|>$ & 0.968 & 0.736 & 1.059 & 0.927 & 0.711 & 0.703 \\
\hline$|E|>3$ & $0.3 \%$ & $0.01 \%$ & $0.26 \%$ & $0.64 \%$ & $0.00 \%$ & $0.13 \%$ \\
\hline$|E|>2$ & 5.0 & 1.8 & 5.1 & 3.8 & 1.3 & 2.1 \\
\hline$|E|>1$ & 32.0 & 36.8 & 31.0 & 32.8 & 37.6 & 38.0 \\
\hline
\end{tabular}

* 1.000 に規格化した。

** 結晶CとDのデータは茫田玉一氏 (大阪大学蛋白質研觉所) 汇提 供していただいた。

によって位相を決めるには，主として次の $\Sigma_{2}$ 式を用いる.

$$
\Sigma_{2}: \quad s E_{h} \approx s \sum_{k} E_{k} \cdot E_{h-k}
$$

ここで， $s$ は“......の符号”を意味する.すなわち， $E_{h}$ の符号は $\boldsymbol{h}=\boldsymbol{k}+(\boldsymbol{h}-\boldsymbol{k})$ の関係に あり，しかも $\left|E_{h}\right|$ 值の大きい $E_{k}$ および $E_{h-k}$ によって表わすことができる。武(2)によっ て与えられる $E_{h}$ の符号が，たとえば十である確率は，

$$
P_{+}\left(E_{h}\right)=\frac{1}{2}+\frac{1}{2} \tanh \frac{\sigma_{3}}{\sigma_{2}^{3 / 2}}\left|E_{i}\right| \sum_{k} E_{k} \cdot E_{h-k}
$$

で与えられる.ここで, $\sigma_{n}=\sum_{j=1}^{N} Z_{j}^{n}, N$ は単位格子ゆの原子数， $Z$ は原子番号である.

さて, 解析の進め方は近似構造を得るまで大体次の 3 つの過程に分㞴られよう. 文献(1)お よび(2)に詳しく述べてあるので，簡単に紹介するにとどめる.

(i) $E$ factor の計算

式(1)によって $\left|E_{h}^{\mathrm{obs}}\right|$ を計算し，1.5〜1.0 以上の反射だけを適当な $\mathrm{I} / \mathrm{O}$ 媒体にアウトプ ットしておく.この際, $\boldsymbol{h}$ の multiplicity を考虑するのを忘れてはならない.

(ii) 位相決定

上で得た各反射に対して $\boldsymbol{h}=\boldsymbol{k}+(\boldsymbol{h}-\boldsymbol{k})$ の関係にある反射 $\boldsymbol{k}$ と $(\boldsymbol{h}-\boldsymbol{k})$ の組（これを interaction pair といら) のすべてを選び出してリストを作る.これを と呼んでいる.

次に原点を固定するために 3 つの射を次のような基準で選び，任意の符号を与える。(a) $\boldsymbol{h}$ が linearly independent (modulo 2). (b) $|E|$ 值が大きい. (c) $\Sigma_{2}$ リスト中でしばしば 見出される.ささらに，(b)，(c)にしたがって，いくつかの反射に A， B などの letter symbol を用いて位相を仮定する。

$\Sigma_{2}$ リスト中の $\boldsymbol{k}$ および $(\boldsymbol{h}-\boldsymbol{k})$ に対し，上で仮定した位相を与えていく。そして式(2)に もとづいて，h の位相（十，一，あるいは symbol の組合わせで与えられる）を決めていく このとき，確率を計算してみて，それがあらかじめ定めておいた基準优 (0.99〜0.97) をこ えたときだけ hにその位相を与える。初期の段階ではただ 1 組の interaction pair から位 相を決めることになるが，位相の決った反射がふえるにつれて，多くの pair を用いて決め 
るようになる。こうして $|E|$ 值の大きい反射から順々に位相を決めていく操作をくり返す が，反復しても位相の決まる反射数が增えなくなれば，収れんしたことになる。

以上の結果, 位相の決った反射数が少なすぎる場合には新しいsymbol を導入して, 同様 な操作をくり返す.

さて, 相当数の反射の位相が symbol を用いて表わされると, 次に symbol 間の相関々係 を検討する.すると, symbol の符号自身が，あるいは $\mathrm{A}=\mathrm{B}$ といらような関倸が見出され るであろう。このような関係は何回も見出されなければそれを受け入れてはならない。

(iii) E map の合成

非対称単位中の原子数の 10 倍くらいの反射の符号が決まれば， $F_{\mathrm{obs}}$ のかわりに $E_{\mathrm{obs}}$ を 係数としたフーリェ合成図, すなわち, E map を計算すると近似的な原子の位置が見出さ れるであろう． $n$ 個の symbol に対して符号を一義的に定めることができない場合には， $2^{n}$ 個の E map を合成してみる必要がある.

\section{4. 構造決定の例}

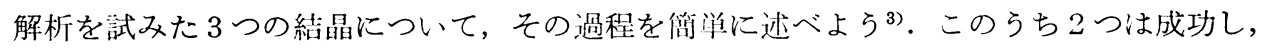
1 つは現在のところ成功していない。とり上げた結晶は次の 3 つである.

I 3.4-furan-dicarboxylic acid dimethylester, $\mathrm{C}_{8} \mathrm{H}_{8} \mathrm{O}_{5}{ }^{(4)} a=12.64, b=8.16$, $c=7.97 \AA, \quad \beta=100.0^{\circ}, \quad P 2_{1} / a, Z=4, \quad N=13 \times 4=52$

II bis (p-trimethylsilanyl-phenyl)-phenyl-phosphine, $\mathrm{C}_{24} \mathrm{H}_{31} \mathrm{PSi}_{2}{ }^{(5)} \quad a=12.75$, $b=11.60, \quad c=19.77 \AA, \quad \beta=119.9^{\circ}, \quad P 2_{1} / c, \quad Z=4, \quad N=27 \times 4=108$

III $\mathrm{C}_{5} \mathrm{H}_{12} \mathrm{O}_{2}{ }^{(6)} \quad a=6.01, \quad b=10.91, c=10.18 \AA, \quad \beta=100^{c}, \quad P 2_{1} / n, \quad Z=4, \quad N=7 \times 4=28$

表 23 つの結晶の解析の比較

\begin{tabular}{|c|c|c|c|c|}
\hline & & 結＼cjkstart晶 & 結＼cjkstart晶 & 結 \\
\hline $\begin{array}{l}\text { त) } \\
\overrightarrow{2} \\
\stackrel{2}{\circ}\end{array}$ & $\begin{array}{l}\text { 強度データ } \\
\text { 钼测反射数 } \\
|E| \geqq 1.5 \text { の反射数 } \\
\text { 同 } \quad \text { 上 } \%\end{array}$ & $\begin{array}{c}h 0 l, 0 k l, \quad h k 0 \sim h k 5 \\
1034 \\
220 \\
21\end{array}$ & $\begin{array}{c}h k 0, h 0 l \sim h 4 l \\
2064 \\
276 \\
13\end{array}$ & $\begin{array}{c}0 k l \sim 4 k l, \quad h k 0 \sim h k 5 \\
807 \\
96 \\
12\end{array}$ \\
\hline 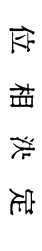 & $\begin{array}{l}\text { symbol の数 } \\
\text { 確率の下限 } \\
\text { 反復 回 数 } \\
\text { 位相の決った反射数 } \\
\text { 同 上 \% } \\
1 \text { 原子あたりの反射数 }\end{array}$ & $\begin{array}{c}2 \\
0.99 \rightarrow 0.97 \\
5+1(\text { hand }) \\
138 \sim 167 \\
63 \sim 76 \\
10 \sim 13\end{array}$ & $\begin{aligned} 3 & \rightarrow 4 \\
0.99 & \rightarrow 0.97 \\
4 & \bullet 2(\text { hand }) \\
174 & \sim 249 \\
63 & \sim 90 \\
6 & \sim 9\end{aligned}$ & $\begin{aligned} 3 & \rightarrow 1 \\
0.99 & \rightarrow 0.98 \\
3 & +1(\text { hand }) \\
42 & \sim 70 \\
44 & \sim 60 \\
6 & \sim 10\end{aligned}$ \\
\hline $\begin{array}{l}\text { W } \\
\text { 疋 }\end{array}$ & $\begin{array}{l}\text { ピークの数 } \\
\text { ピーク高, 最高と最低 } \\
\text { バックグラウンドの最高 } \\
\quad R \quad(\%) *\end{array}$ & $\begin{array}{c}12 \\
468(\mathrm{O}), 220(\mathrm{C}) \\
193 \\
40\end{array}$ & $\begin{array}{c}23 \\
1149(\mathrm{P}), 139(\mathrm{C}) \\
143 \\
53\end{array}$ & $\begin{array}{l}7 \sim 11 \\
228 \sim 130 \\
120 \\
-\end{array}$ \\
\hline & 正しい位相の反射数 & $138 / 138$ & $168 / 172$ & - \\
\hline
\end{tabular}

* Emap のピーク位置に原子を仮定したときの R factor.

以上 3 つの結唱の位相決定を比較して表 2 に示す. 結晶 I については, symbol を2つ(A とC）を用いた。途中の段階で, $\mathrm{A}=+, \mathrm{C}=$ - の関係が得られたが,ささら反復して 138 
の反射の位相が決まったときには， $\mathrm{A}=\mathrm{C}=+$ といら関係が得られこれにもとづいて Emap を計筧したところ分子の形が現われた．さらに 26 個の反射の符号が定まったので（計 167）こ の組についても E map を計算をした.この map を図 1 の上半分に示す。この図はさきの E map よりピークの形がきれいになっている. なお, 図1の下半分は最終的な電子密度分布図 に E map のピーク位置を結んだ線画を重ねた ものであって, 精密化を行ならのに十分な近似 構造が得られているのがわかる.

結晶 IIについても，ほぼ同様な過程をたどっ たが，原子数にくらべて $\mathrm{E}$ map の計算に用い た反射数が少なすぎたので，全原子を E map 上ではっきりととらえることはできなかった。 しかし，化学的な知識とその後のフーリエ図上 で残りの原子を見出すことができた.

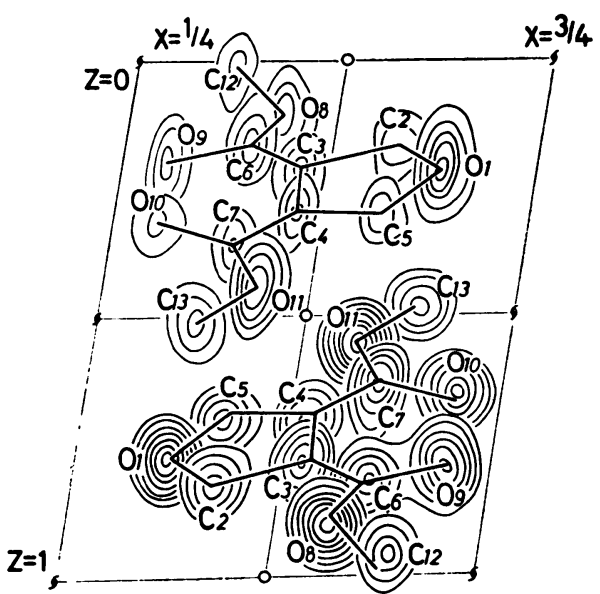

図1上は結晶 Iの 167 ヶの反射を用いて合成 した E map (等高線は任意スケール). 下は最終の電子密度分布図 $\left(2 e \AA^{-8}\right.$ から $1 e \AA ̊ 丿$ きさざみ)に $\mathrm{E}$ map のピークを結 んだ分子の形を重ねてある。

IIII結晶では決めるべき原子数が少ないので，この方法による位相決定は大変やさしいよ らに思われたが，意外にも現在までのところ成功していない，目下その原因を検討中である． なおこの結晶の解析は他の方法により成功している( ${ }^{(6)}$.

以上のわずかの解析の経験からではあるが, 次のような場合には対称心のある場合の symbolic addition 法による位相決定に成功できると思われる.

(1) 単位格子中の原子数があまり多くないこと. $N \leq 120$

(2) $|E| \geq 2.0$ の反射がかなり多くあること.

(3) $|E|$ の大きい反射が index の parity のいろいろなグループにあること.

(4) ある程度の重原子があってもよいと思われるが，それらが特殊位置に存在したり，Iの ような重原子がある場合には困るかもしれない。

さらに実際のテクニックとして，次のよらなことがあげられよう.

(1) symbol の数は少ない方がよい，多くとも4つ以下におさえるべきである．もしそれ以 上導入する必要が生じたならば，その段階で symbol 間の correlation を検討して, symbol 数を减らせてから新しい symbol を入れるとよい.

(2) 確率の下限は, はじめの $2 \sim 3$ サイクルでは $0.99 \sim 0.98$ と高くとり, 相当数の反射の 位相が決まれば思いきって 0.97〜0.96 と下げるとよい。

なお本方法のためのプログラムは, NEAC 2200/500, HITAC 5020, CDC 3600, FAC OM 270-20 用のものはほぼ完成しているので, 御利用下さい.

\section{文献}

1) J. Karle, I. L. Karle, Acta Cryst., 21, 849 (1966).

2) 中津和三「複雑な結晶構造のX線解析」第 2 回シンポジウム抄録 p.19 (1966).

3）中津和三, 岡田安嘉, 田中弘富, 福代 絾, 島田 章, 同上, 第 3 回シンポジゥム抄録 p. 87 
(1967).

4) 岡田安嘉, 中津和三, 島田 章, 日本化学会第21年会, 講演予稿集 I, p.178 (1968).

5）田中弘富, 福代 誠, 中津和三, 島田 章, 同上, p.177 (1968).

6) 中野悦子, 広津 建, 島田 章, 未発表.

日本結晶学会㩆 10,175 (1968)

\section{構造解析における統計法の応用 (II)}

\section{芦田玉 一*}

この数年, 統計法の応用が急速に増加し, 対称心があればかなり複雑な構造をもつ結晶で も解析されることが多くなった。 わが国でも中津氏をはじめ, その他の研究室てもいくつか の成功例が得られている.

ところが対称心がない場合は事情はことなり，報告された成功例は少なく，方法の応用も やや複雑になる．解決されていない技術上の難点（特に自動化を妨げる）もいくつか残って いる. 筆者はそのプログラムを作り, この方法を応用してみて, 不十分ながら $1 \sim 2$ の知見 を得たので簡単に紹介してみたい。

\section{1. 統計法による位相決定法のあらすじ}

この方法で主に使われるのは：

$$
\begin{aligned}
& \varphi_{H} \approx\left\langle\varphi_{K}+\varphi_{H-K}>_{K}\right. \\
& \varphi_{H} \approx \sum_{K}\left|E_{K} E_{H-K}\right|\left(\varphi_{K}+\varphi_{H-K}\right) / \sum_{K}\left|E_{K} E_{H-K}\right| \\
& \tan \varphi_{H} \approx \frac{\sum_{K}\left|E_{K} E_{H-K}\right| \sin \left(\varphi_{K}+\varphi_{H-K}\right)}{\sum_{K}\left|E_{K} E_{H-K}\right| \cos \left(\varphi_{K}+\varphi_{H-K}\right)} \\
& V=\left\langle\left(\varphi_{H}-\left\langle\varphi_{H}\right\rangle\right)^{2}\right\rangle=\left[2 \pi I_{0}(\alpha)\right]^{-1} \int_{-\pi}^{\pi} x^{2} \exp (\alpha \cos x) d x
\end{aligned}
$$

ただし

$$
\begin{aligned}
& \alpha=\left\{\left[\sum_{K} \kappa \cos \left(\varphi_{K}+\varphi_{K-H}\right)\right]^{2}+\left[\sum_{K} \kappa \sin \left(\varphi_{K}+\varphi_{H-K}\right)\right]^{2}\right\}^{1 / 2} \\
& \kappa=2 \sigma_{3} \sigma_{2}^{-3 / 2}\left|E_{H} E_{K} E_{H-K}\right|, \quad \sigma_{n}=\sum_{j} Z_{j}{ }^{n}
\end{aligned}
$$

(1)と(2)は $|E|$ の大きい反射だけについての平均あるいは求和である.

まず大きい $|E|$ をもつ反射の間の $\Sigma_{2}$ - list を作成し，その中に頻繁に現れ，かつ原点を 規定できる 3 ケの反射に任意の位相を与える.投影面に対称心があるときその晶帯の反射を 選べば，位相には $0, \pi, \pm \pi / 2$ などの制限があるので都合がよい，さらに数個の適当な反 射に symbol の位相を与える。この組に(1)を応用して symbolic addition を開始する。はじ めの段階では右辺には一組しか有効なものがない場合が多いので新しい $\varphi_{H}$ を採用するには 特に大きい $|E|$ の組み合せにかぎる必要がある. 採否の基準の一つは variance $V$ で,

* 阪大蛋白研 